УДК 616.895.8:616.891:632.938

Для цитирования: Клюшник Т.П., Андросова Л.В., Зозуля С.А., Отман И.Н., Никитина В.Б., Ветлугина Т.П. Сравнительный анализ воспалительных маркеров при эндогенных и непсихотических психических расстройствах. Сибирский вестник психиатрии и наркологии.2018; 2 (99): 64-69. https://doi.org/10.26617/1810-3111-2018-2(99)-64-69

\title{
Сравнительный анализ воспалительных маркеров при эндогенных и непсихотических психических расстройствах
}

\author{
Клюшник Т.П. ${ }^{1}$, Андросова Л.В. ${ }^{1}$, Зозуля С.А. ${ }^{1}$, Отман И.Н. ${ }^{1}$, Никитина В.Б. ${ }^{2}$, Ветлугина Т.П. ${ }^{2}$ \\ ${ }^{1}$ ФГБНУ «Научный центр психического здоровья» \\ Россия, 115522, Москва, Каширское шоссе, 34 \\ ${ }^{2}$ Научно-исследовательский институт психического здоровья, Томский национальный исследовательский \\ медицинский иентр Российской академии наук (НИИ психического здоровья Томский НИМЦ) \\ Россия, 634014, Томск, ул. Алеутская, 4
}

\section{PEЗЮME}

Цель: сравнительный анализ активности/уровня воспалительных и аутоиммунных маркеров в крови пациентов с эндогенными и непсихотическими психическими расстройствами. Материал и методы: в обследование включены 76 пациентов с эндогенным психозом (ЭП) с разной степенью прогредиентности (по МКБ-10 F20.0 (0-3); F31 (2,5); F33.3) и 73 пациента с непсихотическими психическими расстройствами (по МКБ-10 F43.2; F06.6). Контрольную группу составили 80 человек, сопоставимых по возрасту и полу с пациентами. Активность лейкоцитарной эластазы (ЛЭ) и $\alpha 1$-протеиназного ингибитора $(\alpha 1-П И)$ определяли спектрофотометрическим методом, уровни аАТ к S100b и ОБМ - иммуноферментным методом. Результаты: показано статистически значимое повышение энзиматической активности ЛЭ и функциональной активности $\alpha 1-П И$ по отношению к контролю как в группе пациентов с эндогенными психическими заболеваниями $(\mathrm{p}<0,001 ; \mathrm{p}<0,0001)$, так и в группе пациентов с непсихотическими психическими расстройствами $(\mathrm{p}<0,002 ; \mathrm{p}<0,0001)$, что свидетельствует о вовлеченности воспаления в патофизиологию этих расстройств. Повышенные уровни аАТ к нейроспецифическим антигенам (S100b и ОБМ) имели только пациенты с эндогенными психозами (р<0,001). Выявлено три иммунофенотипа, различающихся преимущественно по соотношению ЛЭ и $\alpha 1-П И . ~ 52 \%$ пациентов с непсихотическими психическими расстройствами имеют «провоспалительный» иммунофенотип, характерный для всех пациентов с эндогенными психическими заболеваниями. Два других иммунофенотипа («нормативный» и «провоспалительный с недостаточной дегрануляционной активностью нейтрофилов») встречаются лишь у пациентов с непсихотическими психическими расстройствами. Заключение: результаты исследования свидетельствуют о вовлеченности воспалительных реакций в патофизиологию непсихотических психических расстройств, которые характеризуются тремя различными иммунофенотипами, один из которых («провоспалительный») характерен также для всех пациентов с эндогенными психозами.

Ключевые слова: лейкоцитарная эластаза, $\alpha 1$-протеиназный ингибитор, эндогенные и непсихотические психические расстройства.

\section{ВВЕДЕНИЕ}

В последнее десятилетие особое внимание уделяется роли воспаления в патогенезе хронических неинфекционных заболеваний, в том числе психических. В многочисленных исследованиях приводятся данные, свидетельствующие о том, что шизофрения, аффективные и шизоаффективные расстройства ассоциированы с активацией иммунной системы. В качестве воспалительных маркеров исследователями рассматриваются провоспалительные цитокины, комплемент, продукты оксидативного стресса, С-реактивный белок и другие белки острой фазы воспаления [1, 2, 3, 4, 5]. В наших клиникобиологических исследованиях показано, что такие маркеры воспаления, как лейкоцитарная эластаза (ЛЭ) и $\alpha 1$-протеиназный ингибитор ( $\alpha 1-П И)$, связаны с активностью текущего патологического процесса в мозге при шизофрении и аффективных психозах $[6,7,8,9]$, а уровень аутоантител к нейроантигенам - белку S100b и основному белку миелина (ОБМ) - с тяжестью этого процесса [8]. Определение этих иммунных показателей в крови пациентов в ходе развития заболевания позволяет оценить остроту и тяжесть текущего патологического про- цесса в мозге, т.е. объективизировать состояние их нервной системы, оценить полноту и качество достигнутой ремиссии, дифференцированно проводить терапию.

Определенный интерес в плане возможной вовлеченности воспалительных реакций в патогенез заболевания представляют также психические расстройства непсихотического уровня, изученные в этом отношении недостаточно. Вместе с тем при иммунологическом исследовании непсихотических психических расстройств (НППР) с позиции клинико-динамического подхода установлены нарушения иммунной защиты на всех стадиях невротического процесса - невротическая реакция (длительность симптоматики до 6 месяцев), невротическое состояние (продолжительность симптоматики до 2 лет), невротическое развитие (сохранение симптоматики более 2 лет). Причем на стадии реакции отмечается самое высокое содержание общего пула периферических Т-лимфоцитов, количество которых при затяжном течении заболевания снижается на фоне повышения гуморальных факторов иммунитета [10, 11]. Клинические проявления НППР вариабельны и полиморфны, что затрудняет их квалификацию по 
основному синдрому и создает трудности для подбора адекватной терапии. Анализ уровня воспалительных маркеров в крови этих пациентов может не только послужить дополнительным лабораторным критерием для их диагностики, но и использоваться для мониторинга состояния пациентов и оптимизации терапии, как и в случае с эндогенными психическими заболеваниями.

Цель - сравнительный анализ активности/уровня воспалительных и аутоиммунных маркеров в крови пациентов с эндогенными и непсихотическими психическими расстройствами.

\section{МАТЕРИАЛ И МЕТОДЫ}

Обследованы 2 группы пациентов. Первую группу составили 76 женщин от 18 до 65 лет (34,0 [29,0; $44,0])$ с эндогенными психозами с разной степенью прогредиентности (по МКБ-10 F20.0 (0-3); F31 (2,5); F33.3), находящихся на лечении в клинике ФГБНУ НЦПЗ, Москва (руководитель отдела по изучению эндогенных психических расстройств и аффективных состояний - академик РАН А.С. Тиганов). Состояние пациентов в приступе квалифицировалось как галлюцинаторно-, депрессивно- и маниакальнобредовое. Психическое состояние больных оценивалось методом клинического наблюдения и психометрически по трём подшкалам PANSS. Вторую группу составили 73 пациента (14 мужчин, 59 женщин) от 24 до 60 лет $(50,0$ [41,0; 58,0]) с НППР. Среди них 38 пациентов (5 мужчин, 33 женщин) с расстройством адаптации (F43.2) и 35 пациентов (9 мужчин, 26 женщин) с органическим эмоционально лабильным (астеническим) расстройством (F06.6). Пациенты с НППР находились на лечении в клинике НИИ психического здоровья Томского НИМЦ (директор - академик РАН Н.А. Бохан, заведующий отделением пограничных состояний - профессор М.М. Аксенов). Психоневрологический статус пациентов характеризовался снижением настроения, беспокойством, неспособностью справляться с физическими нагрузками и сложившейся ситуацией, снижением продуктивности в профессиональной деятельности и ежедневных делах. Для пациентов характерны умственное и физическое истощение, снижение концентрации внимания, трудность собраться с мыслями, ухудшение памяти.

В качестве контроля использовали сыворотку крови 80 соматически и психически здоровых лиц (3 мужчин и 77 женщин) от 25 до 60 лет (34 [31,0; $40,0])$. Иммунологическое исследование сыворотки крови было проведено в лаборатории нейроиммунологии ФГБНУ НЦПЗ (руководитель - профессор Т.П. Клюшник).

Энзиматический метод определения активности ЛЭ. Эластазную активность сыворотки крови, обусловленную на $90 \%$ присутствием в сыворотке

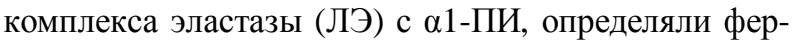
ментативным методом, предложенным В.Л. Доценко и др. [12]. Активность ЛЭ измеряли по скорости расщепления эластазой специфического хромогенного субстрата N-терт-бутоксикарбонил-L-аланин- паранитрофенилового эфира (BOC-Ala-ONp) (ICNBiomedicalInc.) в условиях, подобранных для полного высвобождения фермента из комплекса ЛЭ$\alpha 1-П И$, при $25^{\circ} \mathrm{C}$. Регистрировали изменение оптической плотности с помощью компьютерной программы SWIFT 1000 ReactionKinetics (Version 2.03, BiochromLtd) на спектрофотометре Ultrospec 1100 (Amercham) в течение 3 минут при длине волны 347 нм, соответствующей максимуму поглощения продукта реакции. Активность ЛЭ выражали в нмоль/мин*мл. Чувствительность метода 40 нмоль/мин*мл, коэффициент вариации результатов определения активности ЛЭ в одном и том же образце (10 повторений) не превышает $8 \%$.

Метод определения активности $\alpha 1$-ПИ. Измерение активности $\alpha 1-П И$ в сыворотке крови проводили с помощью спектрофотометрического метода [13]. Метод основан на взаимодействии этого ингибитора с трипсином при использовании в качестве субстрата $\mathrm{N}$ - $\alpha$-бензоил-L-аргининэтилового эфира гидрохлорида (BAEE) (ICNBiomedicalInc): $\alpha 1-П И$ образует с трипсином комплекс, не гидролизующий BAEE. Активность $\alpha 1-П И$ в сыворотке определяли по степени торможения ВАЕЕ-эстеразной активности трипсина определенным количеством исследуемой сыворотки. Регистрировали изменение оптической плотности с помощью компьютерной программы SWIFT 1000 ReactionKinetics (Version 2.03, BiochromLtd) на спектрофотометре Ultrospec 1100 (Amercham) в течение 3 минут при длине волны 253 нм. Активность $\alpha 1$ ПИ выражали в ингибиторных единицах на мл (ИЕ/мл). Чувствительность метода 5 ИЕ/мл, коэффициент вариации результатов определения функциональной активности $\alpha 1-П И$ в одном и том же образце не превышает $5 \%$.

Определение уровня аAT к $S 100 b$ и ОБМ в сыворотке крови проводили методом стандартного твердофазного иммуноферментного анализа (ИФА). Для активации иммунологического планшета (Costar, США) использовали белок S100b или ОБМ (Sigma, США). Для идентификации связавшихся аАТ применяли конъюгат кроличьих антител, меченных пероксидазой хрена к $\operatorname{IgG}$ и $\operatorname{IgM}$ человека (ИМТЕК, Россия). Измерение оптической плотности проводили после остановки реакции при длине волны 492 нм на спектрофотометре MultiskanRC (Labsystems, Финляндия). Уровень аАТ оценивали в единицах оптической плотности (ОП), прямо пропорциональной интенсивности окраски. Чувствительность метода 0,2 ОП, коэффициент вариации результатов определения уровня аАТ в одном и том же образце (10 определений) не превышает $5 \%$.

Статистическая обработка данных осуществлялась с помощью непараметрического статистического программного обеспечения Statistica-7 (для Windows, StatSoft., Inc, США). Межгрупповые различия определяли с использованием теста МаннаУитни. Данные представлены медианой и квартилями - Me [Q1-Q3]. Использовали уровень достоверности $\mathrm{p}<0,05$. 


\section{РЕЗУЛЬТАТЫ И ОБСУЖДЕНИЕ}

В таблице 1 приведены результаты определения анализируемых воспалительных и аутоиммунных маркеров в сыворотке крови пациентов с эндогенными психическими расстройствами и НППР. Приведенные данные свидетельствуют о статистически значимом повышении энзиматической активности ЛЭ и функциональной активности $\alpha 1-П И$ по отношению к контролю не только в группе пациентов с эндогенными психическими заболеваниями, но и в группе пациентов с НППР, что свидетельствует о вовлеченности воспаления в патофизиологию этих расстройств. Повышение уровня аАТ к нейроспецифическим антигенам обнаружено только для пациентов с эндогенными психозами. Как показано ранее, повышенный уровень аутоантител к нейроантигенам в крови пациентов характеризует наиболее тяжелые патологические состояния [8].

Т а б л и ц а 1

Воспалительные и аутоиммунные маркеры в крови пациентов с эндогенными психозами и НППР

\begin{tabular}{|c|c|c|c|}
\hline Показатель & Контроль & $\begin{array}{c}\text { Эндогенные } \\
\text { психозы }\end{array}$ & НППР \\
\hline $\begin{array}{c}\text { Активность ЛЭ, } \\
\text { нмоль/мин мл }\end{array}$ & $\begin{array}{c}213,0 \\
{[196,8 ; 229,6} \\
\end{array}$ & $\begin{array}{c}266,0 \\
225,6 ; 293,6]^{* *} \\
\end{array}$ & $\begin{array}{c}241,4 \\
{[218,7 ; 255,7]^{*}}\end{array}$ \\
\hline $\begin{array}{c}\text { Активность } \alpha 1-П И, \\
\text { ИЕ/мл } \\
\end{array}$ & $\begin{array}{c}33,5 \\
{[30,2 ; 36,7]} \\
\end{array}$ & $\begin{array}{c}41,8 \\
32,6 ; 57,3]^{* * *} \\
\end{array}$ & $\begin{array}{c}41,0 \\
{[35,4 ; 46,8]^{* * *}} \\
\end{array}$ \\
\hline $\begin{array}{c}\text { aAT к S-100b, } \\
\text { ед.опт.пл }\end{array}$ & $\begin{array}{c}0,68 \\
{[0,61 ; 0,75]} \\
\end{array}$ & $\begin{array}{c}0,98 \\
{[0,75 ; 1,04]^{* *}} \\
\end{array}$ & $\begin{array}{c}0,70 \\
{[0,64 ; 0,79]} \\
\end{array}$ \\
\hline $\begin{array}{c}\text { aАТ к ОБМ, } \\
\text { ед.опт.пл }\end{array}$ & $\begin{array}{c}0,73 \\
{[0,62 ; 0,81]} \\
\end{array}$ & $\begin{array}{c}0,97 \\
{[0,71 ; 1,01]^{* *}}\end{array}$ & $\begin{array}{c}0,75 \\
{[0,64 ; 0,84]} \\
\end{array}$ \\
\hline
\end{tabular}

П р и м е ч а н и е. Достоверное изменение по отношению к контролю:*-p<0,002, **-p<0,001, ***-p<0,0001.

При анализе полученных данных обращает на себя внимание значительный разброс иммунологических показателей; в большей мере это касается активности ЛЭ, для которой в ряде случаев наблюдается не только превышение значений, но и их снижение по отношению к контролю; у отдельных пациентов наблюдается активность ЛЭ, находящаяся в диапазоне контрольных значений, сопровождаемая повышением активности $\alpha 1-П И$.

В связи с наблюдаемым разбросом данных вся совокупность полученных иммунологических показателей была разбита на три подгруппы (иммунофенотипы) в зависимости от величины воспалительных маркеров. Подгруппа «А»: воспалительные и аутоиммунные маркеры - в диапазоне контрольных значений (Q1-Q3 контрольной группы соответственно); условно этот иммунофенотип обозначен как «нормативный». Подгруппа «В»: повышение по сравнению с контролем активности ЛЭ и $\alpha 1-П И$ (значения выше Q3 контрольной группы). Уровень аутоантител в рамках этого иммунофенотипа может находиться в контрольном диапазоне либо выходить за его пределы. Таким образом, этот иммунофенотип характеризует активацию иммунных реакций как врожденного, так и (в ряде случаев) адаптивного звена иммунитета; условно этот иммунофенотип обозначен как «провоспалительный». Подгруппа «С»: активность ЛЭ - в диапазоне контрольных зна- чений или ниже, активность $\alpha 1-П И$ - выше Q3 контрольной группы, т.е. этот иммунофенотип характеризуется преимущественным повышением активно-

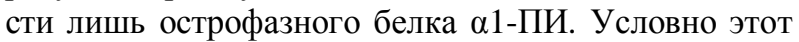
иммунофенотип обозначен как «провоспалительный c недостаточной дегрануляционной активностью нейтрофилов».

В таблице 2 приведены результаты распределения пациентов обеих обследованных групп по выделенным иммунофенотипам.

Т а бл и ц а 2

Распределение пациентов исследуемых групп по выделенным иммунофенотипам

\begin{tabular}{|l|c|c|c|}
\multicolumn{1}{|c|}{ Гру выдела } \\
\cline { 2 - 4 } & \multicolumn{3}{|c|}{ Иммунофенотипы } \\
\hline Контроль & $80 / 100 \%$ & - & - \\
\hline Эндогенные психозы & - & $76 / 100 \%$ & - \\
\hline $\begin{array}{l}\text { Непсихотические психиче- } \\
\text { ские расстройства }\end{array}$ & $17 / 23,3 \%$ & $38 / 52 \%$ & $18 / 24,7 \%$ \\
\hline
\end{tabular}

Иммунофенотип «А» выявлен в крови 23,3\% пациентов с НППР и характеризуется иммунными показателями в диапазоне контрольных значений, что, вероятно, свидетельствует об отсутствии значимого патологического процесса в мозге пациентов на момент их обследования. Приведенные в таблице данные свидетельствуют, что иммунофенотип «В» характеризует всех пациентов с эндогенными психическими расстройствами и $52 \%$ пациентов с НППР. Таким образом, большинство обследованных пациентов характеризуются повышением активности как ЛЭ, так и острофазного белка $\alpha 1-П И$.

Рост активности ЛЭ в крови в ходе развития воспалительного ответа является результатом дегрануляции активированных нейтрофилов - главнейшего клеточного компонента врожденного иммунитета, инициирующих и координирующих иммунный ответ как на внедрение инфекционного агента, так

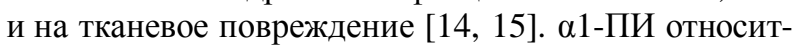
ся к острофазным белкам, синтезирующимся в печени, основным индуктором синтеза которого является провоспалительный интерлейкин ИЛ-6 [16]. Функциональная роль $\alpha 1-П И$ заключается в ингибировании активности протеаз, в первую очередь лейкоцитарной эластазы, что ограничивает ее деструктивный потенциал. Таким образом, повышение активности ЛЭ и $\alpha 1-П И$ характеризует активацию врожденного иммунитета и развитие воспалительной реакции, направленной на восстановление нарушенного гомеостаза организма.

Что касается иммунофенотипа «С», характеризующегося преимущественным повышением активности лишь острофазного белка $\alpha 1-П И$, он также не встречается у пациентов с эндогенными психическими расстройствами и выявлен у $24,7 \%$ пациентов с НППР.

Снижение активности ЛЭ по отношению к контролю, сочетающееся с повышенной активностью a1-ПИ, вероятно, характеризует функциональные нарушения нейтрофилов. Нейтрофилы, как известно, являются важными эффекторными клетками 
воспаления и следствием их функциональной недостаточности, описанной, в частности, при ряде хронических соматических заболеваний, является неспособность сформировать адекватный функциональный иммунный ответ на протекающий патологический процесс $[17,18]$.

\section{ЗАКЛЮЧЕНИЕ}

Таким образом, результаты настоящего исследования свидетельствуют о вовлеченности воспалительных реакций в патофизиологию таких форм НППР, как расстройства адаптации и органические эмоционально лабильные (астенические) расстройства. Показано, что эти расстройства характеризуются тремя иммунофенотипами, различающимися преимущественно по соотношению ЛЭ и $\alpha 1-П И$. $52 \%$ пациентов с НППР имеют «провоспалительный» иммунофенотип, характерный для всех пациентов с эндогенными психозами. В связи с выявлением при данных формах НППР иммунофенотипов, не свойственных эндогенным психическим заболеваниям, в дальнейшем предполагается исследовать корреляции между иммунофенотипами и клиническими особенностями течения этих расстройств.

\section{КОНФЛИКТ ИНТЕРЕСОВ}

Авторы заявляют об отсутствии конфликта интересов в связи с публикацией данной статьи.

\section{ИСТОЧНИК ФИНАНСИРОВАНИЯ}

Авторы заявляют об отсутствии финансирования при проведении исследования.

\section{СООТВЕТСТВИЕ ПРИНЦИПАМ ЭТИКИ}

Работа соответствует этическим стандартам Хельсинкской декларации ВМА (протокол заседания локального этического комитета при НИИ психического здоровья Томского НИМЦ № 53 от 01.10.2012, Дело № 53/1.2012; протокол № 410 от 11 01.2018 г. при ФГБНУ НЦПЗ).

\section{ЛИТЕРАТУРА}

1. Müller N. Immunology of schizophrenia. Neuroimmunomodulation. 2014;21(2-3):109-16. doi: 10.1159/000356538. Epub 2014 Feb 14.

2. Kim Y.K., Na K.S., Myint A.M., Leonard B.E. The role of proinflammatory cytokines in neuroinflammation, neurogenesis and the neuroendocrine system in major depression. Prog Neuropsychopharmacol Biol Psychiatry. 2016; Jan 4; 64: 277-84. doi: 10.1016/j.pnpbp.2015.06.008. Epub 2015 Jun 23.

3. Miller B.J., Goldsmith D.R. Towards an Immunophenotype of Schizophrenia: Progress, Potential Mechanisms, and Future Directions. Neuropsychopharmacology. 2017; Jan; 42 (1): 299317. doi: 10.1038/npp.2016.211. Epub 2016 Sep 22.

4. Misiak B., Stańczykiewicz B., Kotowicz K., RybakowskiJ.K., Samochowiec J., Frydecka D. Cytokines and C-reactive protein alterations with respect to cognitive impairment in schizophrenia and bipolar disorder: A systematic review. Schizophr Res. 2017; Apr 13. pii: S0920-9964(17)30202-5. doi: 10.1016/j.schres.2017.04.015

5. Leonard B.E. Inflammation and depression: a causal or coincidental link to the pathophysiology? Acta Neuropsychiatr. 2018; Feb; 30 (1): 1-16. doi: 10.1017/neu.2016.69. Epub 2017 Jan 23.
6. Клюшник Т.П., Андросова Л.В., Симашкова Н.В., Зозуля С.А., Отман И.Н., Коваль-Зайцев А.А. Состояние врожденного и приобретенного иммунитета у детей с психотическими формами расстройств аутистического спектра. Журнал неврологии и психиатрии им. С.С. Корсакова. 2011; 8: 41-45.

7. Зозуля С.А., Олейчик И.В., Андросова Л.В., Отман И.Н., Сарманова 3.В., Столяров С.А., Бизяева А.С., Юнилайнен О.А., Клюшник Т.П. Мониторинг течения эндогенных психозов по иммунологическим показателям. Психическое здоровье. 2017 ; 1: 11-18.

8. люшник Т.П., Зозуля С.А., Олейчик И.В. Маркеры активации иммунной системы в мониторинге течения эндогенных психических заболеваний. Биологические маркеры шизофрении: поиск и клиническое применение / под ред. Н.А.Бохана, С.А. Ивановой. Новосибирск: Изд-во СО РАН, 2017: 34-46.

9. Клюшник Т.П., Зозуля С.А., Андросова Л.В., Сарманова 3.В., Отман И.Н., Пантелеева Г.П., Олейчик И.В., Копейко Г.И., Борисова О.А., Абрамова Л.И., Бологов П.В., Столяров С.А. Лабораторная диагностика в мониторинге пациентов с эндогенными психозами («Нейро-Иммуно-Тест»). Медицинская технология. 2-е издание (дополненное). М.: Медицинское информационное агентство, 2016.

10. Иванова С.А. Психонейроиммуномодуляция в клинике и терапии невротических и аффективных расстройств: Дис. ... д.м.н. Томск, 2000.

11. Аксенов М.М., Гычев А.В., Белокрылова М.Ф., Семке В.Я., Ветлугина Т.П., Никитина В.Б., Перчаткина О.Э., Рудницкий В.А., Левчук Л.А., Костин А.К. Стрессоустойчивость и дезадаптация при непсихотических психических расстройствах (итоги комплексной темы НИР ФГБУ «НИИПЗ» СО РАМН, 2009-2012 гг.). Сибирский вестник психиатрии и наркологии. 2013; 4 (79): 11-17.

12. Доценко В.Л., Нешкова Е.А., Яровая Г.А. Выявление лейкоцитарной эластазы человека из комплекса с плазменным $\alpha 1$ протеиназным ингибитором по её энзиматической активности с синтетическим субстратом. Bопросы меицинской химии. 1994; 40 (3): 20-25.

13. Нартикова В.Ф., Пасхина Т.С. Унифицированный метод определения активности альфа-1-антитрипсина и альфа-2макроглобулина в сыворотке (плазме) крови человека. Вопросы медицинской химии. 1979; 25 (4): 494-499.

14. Lehnardt S. Innate immunity and neuroinflammation in the CNS: the role of microglia in Toll-like receptor-mediated neuronal injury. Glia. 2010; Feb; 58 (3): 253-63. doi: 10.1002/glia.20928

15. Mantovani A., Cassatella M.A., Costantini C., Jaillon S. Neutrophils in the activation and regulation of innate and adaptive immunity. Nat Rev Immunol. 2011; Jul 25; 11 (8): 519-531. doi: 10.1038/nri3024

16. Mayadas T.N., Cullere X., Lowell C.A. The multifaceted functions of neutrophils. Annu Rev Pathol. 2014; 9: 181-218. doi: 10.1146/annurev-pathol-020712-164023 Epub 2013 Sep 16.

17. Волель Б., Макух Е., Лебедева М., Попова Е., Шоломова В., Андросова Л., Мухин Н., Бекетов В., Бровко М., Клюшник Т. Клинико-лабораторные маркеры астенического синдрома у больных саркоидозом. Врач. 2016; 7: 74-76.

18. Клименко Н.А., Шелест М.А. Функциональная активность нейтрофилов периферической крови при хроническом бронхите. Научные ведомости БелГУ. Серия Медицина. Фармация. 2013; 11 (154), вып. 22: 129-132.

Поступила в редакцию 1.02 .2018 Утверждена к печати 2.04.2018

Клюшник Татьяна Павловна, профессор, д.м.н., директор центра, руководитель лаборатории нейроиммунологии. Андросова Любовь Васильевна, к.б.н., ведущий научный сотрудник лаборатории нейроиммунологии. Зозуля Светлана Александровна, к.б.н., ведущий научный сотрудник лаборатории нейроиммунологии. Отман Ирина Николаевна, к.б.н., научный сотрудник лаборатории нейроиммунологии. Никитина Валентина Борисовна, д.м.н., заведующая лабораторией клинической психонейроиммунологии и нейробиологии. Ветлугина Тамара Парфеновна, д.б.н., профессор, заслуженный деятель науки РФ, ведущий научный сотрудник лаборатории клинической психонейроиммунологии и нейробиологии, руководитель отдела биологической психиатрии и наркологии. 
For citation: Klyushnik T.P., Androsova L.V., Zozulya S.A., Otman I.N., Nikitina V.B., Vetlugina T.P. Comparative analysis of inflammatory markers in endogenous and non-psychotic mental disorders. Siberian Herald of Psychiatry and Addiction Psychiatry. 2018; 2 (99): 64-69. https://doi.org/10.26617/1810-3111-2018-2(99)-64-69

\title{
Comparative analysis of inflammatory markers in endogenous and non-psychotic mental disorders
}

\section{Klyushnik T.P. ${ }^{1}$, Androsova L.V. ${ }^{1}$, Zozulya S.A. ${ }^{1}$, Otman I.N. ${ }^{1}$, Nikitina V.B. ${ }^{2}$, Vetlugina T.P. ${ }^{2}$}

\author{
${ }^{1}$ Mental Health Research Center \\ Kashirskoye Shosse 34, 115522, Moscow, Russian Federation \\ ${ }^{2}$ Mental Health Research Institute, Tomsk National Research Medical Center, Russian Academy of Sciences \\ Aleutskaya Street 4, 634014, Tomsk, Russian Federation
}

\section{ABSTRACT}

Objective of the study: comparative analysis of the activity/level of inflammatory and autoimmune markers in the blood of patients with endogenous and non-psychotic mental disorders. Material and Methods: the study included 76 patients with endogenous psychosis (EP) of different degree of progression (according to ICD-10 F20.0 (0-3); F31 (2,5); F33.3) and 73 patients with non-psychotic mental disorders (according to ICD-10 F43.2; F06.6). Control group consisted of 80 persons matched in age and sex with patients. Activity of leukocytic elastase (LE) and $\alpha 1$-proteinase inhibitor ( $\alpha 1$-PI) was identified with use of spectrophotometric method, levels of aAT to S100b and MBP - with use of immunoenzyme method. Results: the statistically significant increase in enzymatic activity of LE and functional activity of $\alpha 1-\mathrm{PI}$ in relation to control both in the group of patients with endogenous mental diseases $(\mathrm{p}<0.001 ; \mathrm{p}<0.0001$, respectively) and in the group of patients with non-psychotic mental disorders ( $<<0.002$; $\mathrm{p}<0.0001)$ was shown that gave evidence of the involvement of the inflammation in pathophysiology of these disorders. Only patients with endogenous psychoses had increased levels of aAT to neurospecific antigens (S100b and MBP) (p<0.001). Three immunophenotypes, different primarily in ratio of LE and a1-PI, were revealed. 52\% of patients with non-psychotic mental disorders had pro-inflammatory immunophenotype, typical for all patients with endogenous mental diseases. Two other immunophenotypes (normative and pro-inflammatory with deficient degranulation activity of neutrophils) were found only in patients with nonpsychotic mental disorders. Conclusion: findings of this study gave evidence of the involvement of inflammatory reactions in pathophysiology of non-psychotic mental disorders that were characterized by three different immunophenotypes one of which (pro-inflammatory) was typical also for all patients with endogenous psychoses.

Keywords: addiction, cytokines, electroencephalogram, olfaction, pain, sensation seeking.

\section{REFERENCES}

1. Müller N. Immunology of schizophrenia. Neuroimmunomodulation 2014; 21 (2-3): 109-16. doi: 10.1159/000356538. Epub 2014 Feb 14.

2. $\quad$ Kim Y.K., Na K.S., Myint A.M., Leonard B.E. The role of proinflammatory cytokines in neuroinflammation, neurogenesis and the neuroendocrine system in major depression. Prog Neuropsychopharmacol Biol Psychiatry. 2016; Jan 4; 64: 277-84. doi: 10.1016/j.pnpbp.2015.06.008. Epub 2015 Jun 23.

3. Miller B.J., Goldsmith D.R. Towards an Immunophenotype of Schizophrenia: Progress, Potential Mechanisms, and Future Directions. Neuropsychopharmacology. 2017; Jan; 42 (1): 299317. doi: 10.1038/npp.2016.211. Epub 2016 Sep 22.

4. Misiak B., Stańczykiewicz B., Kotowicz K., Rybakowski J.K., Samochowiec J., Frydecka D. Cytokines and C-reactive protein alterations with respect to cognitive impairment in schizophrenia and bipolar disorder: A systematic review. Schizophr Res. 2017; Apr 13. pii: S0920-9964(17)30202-5. doi: 10.1016/j.schres.2017.04.015

5. Leonard B.E. Inflammation and depression: a causal or coincidental link to the pathophysiology? Acta Neuropsychiatr. 2018; Feb; 30 (1): 1-16. doi: 10.1017/neu.2016.69. Epub 2017 Jan 23.

6. Klyushnik T.P., Androsova L.V., Simashkova N.V., Zozulya S.A., Otman I.N., Koval-Zaitsev A.A. Sostojanie vrozhdennogo i priobretennogo immuniteta u detej s psihoticheskimi formami rasstrojstv autisticheskogo spektra [Innate and adaptive immunity in children with psychotic forms of autism spectrum disorders]. Zhurnal nevrologii i psihiatrii im. S.S. Korsakova - S.S. Korsakov Journal of Neurology and Psychiatry. 2011; 8: 41-45 (in Russian).

7. Zozulya S.A., Oleichik I.V., Androsova L.V., Otman I.N., Sarmanova Z.V., Stolyarov S.A., Bizyaeva A.S., Yunilainen O.A., Klyushnik T.P. Monitoring techenija jendogennyh psihozov po immunologicheskim pokazateljam [Monitoring trend of endogenous psychoses by immunological parameters]. Psihicheskoe zdorov'e - Mental Health. 2017; 1: 11-18 (in Russian)
8. Klyushnik T.P., Zozulya S.A., Oleichik I.V. Markery aktivacii immunnoj sistemy $\mathrm{v}$ monitoringe techenija jendogennyh psihicheskih zabolevanij [Markers of activation of immune system in monitoring of course of endogen ousmental diseases]. Biologicheskie markery shizofrenii: poisk i klinicheskoe primenenie [Biological markers of schizophrenia: search and clinical use] / N.A. Bokhan, S.A. Ivanova, eds. Novosibirsk: Publishing House of SB RAS, 2017: 34-46 (in Russian).

9. Klyushnik T.P., Zozulya S.A., Androsova L.B., Sarmanova Z.V., Otman I. N., Panteleeva G.P., Oleichik I.V., Kopeiko G.I., Borisova O.A., Abramova L.I., Bologov P.V., Stolyarov S.A. Laboratornaja diagnostika $\mathrm{v}$ monitoringe pacientov $\mathrm{s}$ jendogennymi psihozami ("Nejro-Immuno-Test") [Laboratory diagnosis in monitoring of pateints with endogenous psychoses ("NeuroImmuno-Test)]. Medical technology. 2nd edition, updated. Moscow: Medicinskoe informacionnoe agentstvo, 2016 (in Russian).

10. Ivanova S.A. Psikhoneyroimmunomodulyatsiya $\mathrm{v}$ klinike i terapii nevroticheskikh i affektivnykh rasstroystv [Psychoneuroimmunomodulationin clinical picture and therapy of neurotic and affective disorders]. MD thesis. Tomsk, 2000 (in Russian).

11. Axenov M.M., Gychev A.V., Belokrylova M.F., Semke V.Ya., Vetlugina T.P., Nikitina V.B., Perchatkina O.E., Rudnitsky V.A., Levchuk L.A., Kostin A.K. Stressoustoychivost i dezadaptatsiya pri nepsikhoticheskikh psikhicheskikh rasstroystvakh (itogi kompleksnoy temy NIR FGBU "NIIPZ" SO RAMN, 2009-2012 gg.) [Stress resistance and desadaptation in nonpsychotic mental disorders (results of complex theme of research work of Mental Health Research Institute SB RAMSci, 20092012)]. Sibirskiy vestnik psikhiatrii i narkologii - Siberian Herald of Psychiatry and Addiction Psychiatry. 2013; 4 (79): 11-17 (in Russian).

12. Dotsenko V.L., Neshkova E.A., Iarovaia G.A. Vyjavlenie lejkocitarnojj elastazy cheloveka iz kompleksa s plazmennym $\alpha 1$ - 
proteinaznym ingibitorom po ejo jenzimaticheskoj aktivnosti s sinteticheskim substratom [Detection of human leukocyte elastase from a plasma alpha-1-proteinase inhibitor complex by its enzymatic activity with synthetic substrate]. Voprosy med. Himii Problems of Medical Chemistry. 1994; 40 (3): 20-25 (in Russian).

13. Nartikova V.F., Pashina T.S. Unificirovannyj metod opredelenija aktivnosti alfa-1-antitripsinai $\alpha$ i alfa-2-makroglobulina v syvorotke (plazme) krovi cheloveka [A method for estimation of $\alpha 1$-antitrypsin and of $\alpha 2$-macroglobulin in human blood serum (plasma) in normal state and under some pathological conditions]. Voprosy med. Himii - Problems of Medical Chemistry. 1979; 25 (4): 494-499 (in Russian).

14. Lehnardt S. Innate immunity and neuroinflammation in the CNS: the role of microglia in Toll-like receptor-mediated neuronal injury. Glia. 2010; Feb; 58 (3): 253-63. doi: 10.1002/glia.20928

15. Mantovani A., Cassatella M.A., Costantini C., Jaillon S. Neutrophils in the activation and regulation of innate and adaptive immunity. Nat Rev Immunol. 2011; Jul 25; 11 (8): 519-531. doi: $10.1038 /$ nri3024
16. Mayadas T.N., Cullere X., Lowell C.A. The multifaceted functions of neutrophils. Annu Rev Pathol. 2014; 9: 181-218. doi: 10.1146/annurev-pathol-020712-164023 Epub 2013 Sep 16.

17. Volel B., Makukh E., Lebedeva M., Popova E., Sholomova V., Androsova L., Mukhin N., Beketov V., Brovko M., Klyushnik T. Kliniko-laboratornye markery astenicheskogo sindroma $\mathrm{u}$ bolnyh sarkoidozom [Clinical and laboratory markers of asthenic syndrome in patients with sarcoidosis]. Vrach-Physician. 2016; 7: 74-76 (in Russian).

18. Klimenko N.A., Shelest M.A. Funktsional'naya aktivnost' neitrofilov perifericheskoi krovi pri hronicheskom bronkhite [Functional activity of peripheral blood neutrophils in chronic bronchitis]. Nauchnye vedomosti BelGU. Seriya Meditsina. Farmatsiya - Belgorod State University Scientific Bulletin. Medicine. Pharmacy. 2013; 11 (154), 22: 129-132 http://dspace.bsu.edu.ru/handle/123456789/19378 (in Russian).

Received February 1.2018 Accepted April 2.2018

Klyushnik Tatyana P. MD, Prof., Director of the Centre, Head of Neuroimmunology Laboratory, Mental Health Research Center, Moscow, Russian Federation.

Androsova Lyubov V., PhD, Biology, lead researcher of Neuroimmunology Laboratory, Mental Health Research Center, Moscow, Russian Federation. Zozulya Svetlana A., PhD, Biology, lead researcher of Neuroimmunology Laboratory, Mental Health Research Center, Moscow, Russian Federation. Otman Irina N., PhD, Biology, researcher of Neuroimmunology Laboratory, Mental Health Research Center, Moscow, Russian Federation. Nikitina Valentina B., MD, Head of the Laboratory of Clinical Psychoneuroimmunology and Neurobiology, Mental Health Research Institute, Tomsk National Research Medical Center, Russian Academy of Sciences, Tomsk, Russian Federation.

Vetlugina Tamara P., ScD, Prof., lead researcher of assistant of the Laboratory of Clinical Psychoneuroimmunology and Neurobiology, Mental Health Research Institute, Tomsk National Research Medical Center, Russian Academy of Sciences, Tomsk, Russian Federation.

Klyushnik Tatyana P., klushnik2004@mail.ru 